\title{
Specific expression and methylation of SLIT1, SLIT2, SLIT3, and miR-218 in gastric cancer subtypes
}

\author{
MIRANG KIM $^{1,2}$, JONG-HWAN KIM ${ }^{1,2}$, SU-JIN BAEK ${ }^{1,2}$, SEON-YOUNG KIM ${ }^{1,2}$ and YONG SUNG KIM ${ }^{1,2}$ \\ ${ }^{1}$ Genome Research Center, Korea Research Institute of Bioscience and Biotechnology (KRIBB); \\ ${ }^{2}$ Department of Functional Genomics, University of Science and Technology, Daejeon 34141, Republic of Korea
}

Received December 20, 2015; Accepted January 27, 2016

DOI: $10.3892 /$ ijo.2016.3473

\begin{abstract}
SLIT has been suggested as a key regulator of cancer development and a promising therapeutic target for cancer treatment. Herein, we analyzed expression and methylation of SLIT1/SLIT2/SLIT3 in 11 gastric cancer cell lines, 96 paired gastric tumors and adjacent normal gastric tissues, and 250 gastric cancers provided by The Cancer Genome Atlas. Methylation of SLIT1/SLIT2/SLIT3 was found both in early gastric cancers, and in advanced gastric cancers. Even normal gastric tissue showed increased methylation of SLITI and SLIT3 that correlated with patient age. Furthermore, epigenetic inactivation of SLIT occurred in a gastric cancer subtype-dependent manner. SLIT2 and SLIT3 expression was reduced in Epstein-Barr virus-positive and microsatellite instability subtypes, but increased in the genomically stable subtype. Expression of miR-218 correlated negatively with methylation of SLIT2 or SLIT3. These findings suggest that a molecular subtype-specific therapeutic strategy is needed for targeting SLITs and miR-218 in treatment of gastric cancer.
\end{abstract}

\section{Introduction}

Gastric cancer is a heterogeneous disease that has its basis in various genetic and epigenetic alterations. Based on Lauren's classification, gastric cancer has been divided into two histological subtypes, namely the intestinal type and diffuse type (1). Recent advances in high-throughput analysis have delivered new insights into the heterogeneity underlying distinct molecular subtypes of gastric cancer. The Cancer Genome Atlas (TCGA) network investigated exome sequences, copy-number alterations, gene expression, DNA methylation, and protein activities of gastric cancers and classified gastric cancers into four subtypes: Epstein-Barr virus (EBV)-positive,

Correspondence to: Dr Yong Sung Kim, Genome Research Center, Korea Research Institute of Bioscience and Biotechnology (KRIBB), 125 Gwahak-ro, Yuseong-gu, Daejeon 34141, Republic of Korea E-mail: yongsung@kribb.re.kr

Key words: SLIT1, SLIT2, SLIT3, miR-218, methylation, gastric cancer microsatellite instability (MSI), genomically stable (GS), and chromosomal instability (CIN) (2). Nearly $9 \%$ of gastric cancer is EBV-positive (3), for which methylation of tumor suppressor genes is a key abnormality (4). MSI is a common feature of gastric cancers that occurs in $15-30 \%$ of cases (5). DNA mismatch repair deficiency such as methylation of the MLH1 promoter increases the frequency of mutations across the genome, creating MSI (5). Not only MLH1 but also many other tumor suppressor genes are frequently hypermethylated in MSI-positive gastric cancer (6). The GS subtype is characterized by the enrichment of diffuse-type gastric cancer, which is an aggressive, invasive, and stem-like histological subtype (2). This molecular classification has important biological and clinical implications for basic research, diagnosis, and drug treatment of gastric cancer.

SLIT proteins are highly conserved secreted glycoproteins and the main ligands for roundabout receptors (ROBOs) (7). The SLIT/ROBO pathway plays an important part in cellsignaling pathways including axon guidance, cell migration, cell motility, and angiogenesis. Recent studies indicate that SLIT proteins have important roles in tumorigenesis, cancer progression, and metastasis $(8,9)$. Three genes encoding SLITs (SLIT1, SLIT2 and SLIT3) have been characterized in mammals. SLIT1 is located on human chromosome 10q24.1, SLIT2 is on 4p15.31, and SLIT3 is on 5q34-q35.1. SLIT2 regulates the $\beta$-catenin/TCF and PI3K/AKT signaling pathways and enhances cell-cell adhesion in breast cancer (10). Knockdown of SLIT2 promotes gastric cancer cell proliferation and migration via activation of AKT/ $\beta$-catenin signaling (11). SLIT2 and SLIT3 are frequently methylated and downregulated in various cancers such as breast (12), colorectal (13), cervical (14), and lung (12), but their methylation status in gastric cancer has not been unequivocally defined.

miR-218 is an intronic microRNA (miRNA) co-expressed with its host genes, SLIT2 and SLIT3 (15). The mature form of miR-218 is generated from two separate loci, $m i R-128-1$ and $m i R-218-2$, which are located within the introns of SLIT2 and SLIT3, respectively (16). miR-218 functions as a tumor suppressor, inhibiting cell invasion and metastasis (17). In gastric cancer cells deficient in miR-218 expression, ectopic expression of miR-218 suppresses both ROBO1 expression and tumor cell invasiveness/metastasis (18).

The genome-wide DNA methylation profiling of gastric cancer reported here shows that the $\mathrm{CpG}$ islands of SLIT1, 
SLIT2 and SLIT3 are hypermethylated. We analyzed expression and methylation of SLITs in gastric cancer cell lines and primary gastric tumors. We also analyzed subtype-specific methylation and expression of SLITS using TCGA data. Furthermore, we examined the correlation between miR-218 expression and $\mathrm{CpG}$ island methylation of SLIT2 or SLIT3 in gastric cancer.

\section{Materials and methods}

Cell lines and tissue samples. Eleven gastric cancer cell lines were obtained from the Korean Cell Line Bank and were cultured in RPMI-1640 supplemented with $10 \%$ fetal bovine serum and $1 \%$ antibiotic-antimycotic solution (Invitrogen, Carlsbad, CA, USA). Ninety-six paired frozen gastric tumor tissues and normal adjacent tissues were collected from the Tissue Bank at Chungnam National University Hospital. All samples were obtained with informed consent, and their use was approved by the institutional review board (19).

Methylated DNA-binding domain sequencing (MBD-seq). MBD-seq was performed as described (20). Briefly, methylated DNA was precipitated from $1 \mu \mathrm{g}$ of fragmented genomic DNA via binding to the methyl-CpG-binding domain of human MBD2 protein using the MethylMiner methylated DNA enrichment kit (Invitrogen). The methylated DNA fragments were ligated to a pair of adaptors for sequencing on the Illumina HiSeq 2500 sequencing system. The ligation products were size fractioned to obtain 250-350-bp fragments on a $2 \%$ agarose gel and subjected to 18 cycles of PCR amplification. Cluster generation and 100 cycles of pairedread sequencing were done. The sequences were mapped to the human genome (UCSC hg19). The sequencing data have been deposited in the NCBI Gene Expression Omnibus (GEO) under accession no. GSE46595.

Quantitative reverse transcription ( $q R T)$-PCR. qRT-PCR was performed as described (21). RNA was isolated using the RNeasy kit (Qiagen, Valencia, CA, USA) and treated with DNase I (Promega, Madison, WI, USA). Total RNA (5 $\mu \mathrm{g})$ was reverse-transcribed into cDNA using SuperScript II (Invitrogen). qRT-PCR was done in a Bio-Rad CFX96 real-time PCR detection system (Bio-Rad, Foster City, CA, USA). cDNA (100 ng) was amplified in a $15-\mu 1$ reaction containing 2X SYBR Premix EX Taq (Takara, Shiga, Japan) using the primer sets listed in Table I. Samples were heated to $95^{\circ} \mathrm{C}$ for $30 \mathrm{sec}$, followed by 39 cycles of $95^{\circ} \mathrm{C}$ for $30 \mathrm{sec}, 60^{\circ} \mathrm{C}$ for $30 \mathrm{sec}$, and $72^{\circ} \mathrm{C}$ for $30 \mathrm{sec}$. The gene encoding $\beta$-actin was used as an internal control. Each expression level was expressed as the cycle threshold (CT) value, and the difference in $\mathrm{CT}$ values for the gene and $\beta$-actin was calculated. Each mRNA level in tumors is presented relative to that of the normal tissue counterpart. If the expression level in the tumor was less than half that in paired normal tissue, it was considered a 'loss of expression'.

Methylation-specific PCR (MSP). MSP was performed as described (22). Genomic DNA was modified by sodium bisulfite using the Ez DNA Methylation kit (Zymo Research, Orange, CA, USA). Bisulfite-modified DNA (50 ng) was amplified in a $20-\mu l$ reaction with primers specific for methylated DNA (Table I) as follows: $94^{\circ} \mathrm{C}$ for $5 \mathrm{~min}, 35$ cycles of $94^{\circ} \mathrm{C}$ for $30 \mathrm{sec}$, at the given annealing temperature for $30 \mathrm{sec}$, and $72^{\circ} \mathrm{C}$ for $60 \mathrm{sec}$, followed by $72^{\circ} \mathrm{C}$ for $10 \mathrm{~min}$. The PCR products were separated on a $3 \%$ agarose gel and visualized with ethidium bromide staining.

Pyrosequencing. Methylation was quantified by pyrosequencing at selected $\mathrm{CpG}$ sites in SLIT genes. For SLIT1, CpG sites at $99,107,110,112,114,122$, and 124 bases from the transcription start site (TSS) were analyzed. For SLIT2, CpG sites at $-1,489,-1,486,-1,478,-1,472,-1,466,-1,460,-1,458$, and $-1,453$ bases from the TSS were analyzed. For SLIT3, CpG sites at 77, 80, 83, 86, 90, 95, and 100 bases from the TSS were analyzed. Pyrosequencing was performed as described (19) using primers listed in Table I. Bisulfite-modified DNA (100 ng) was used in a $25-\mu 1$ reaction containing the primer set and 2X Premix EX Taq (Takara). All samples were heated to $95^{\circ} \mathrm{C}$ for $5 \mathrm{~min}$ and then amplified for 50 cycles of $95^{\circ} \mathrm{C}$ for $30 \mathrm{sec}, 60^{\circ} \mathrm{C}$ for $40 \mathrm{sec}$, and $72^{\circ} \mathrm{C}$ for $30 \mathrm{sec}$, followed by a final extension step at $72^{\circ} \mathrm{C}$ for $5 \mathrm{~min}$. Pyrosequencing reactions were carried out using a sequencing primer and the PSQ HS 96A System (Biotage, Uppsala, Sweden) according to the specifications of Biotage.

5-Aza-2'-deoxycytidine (5-Aza-dC) treatment. The two gastric cancer cells SNU-601 and SNU-638 were seeded at a density of $1 \times 10^{6}$ cells $/ 10-\mathrm{cm}$ dish 1 day before drug treatment. The cells were treated with $10 \mu \mathrm{M} 5$-Aza-dC (Sigma, St. Louis, MO, USA) every $24 \mathrm{~h}$ for 3 days and then harvested. Total RNA was prepared for each cell sample, and changes in SLIT expression were measured by qRT-PCR as described above.

Statistical analysis. The significance of differences in $\mathrm{CpG}$ region hypermethylation between normal and tumor tissues was inferred using the paired t-test. The correlation between downregulation of SLITS and hypermethylation of SLIT CpG regions was inferred from the Pearson's correlation test. A linear model was used to understand the contribution of each clinical variable to the observed differences in SLIT expression and promoter hypermethylation. Six clinical parameters were used: tumor (tumor vs. normal), tumor depth (early vs. advanced gastric cancer), age, gender, TNM stage (IA, IB, II, IIIA, IIIB and IV), and Lauren's classification (intestinal vs. diffuse). The model formula was SLIT - tumor + histology + depth + age + gender + stage + Lauren. The R statistical language (http://cran.r-project.org) was used for all statistical tests. To compare characteristics of the different groups of patients, the t-test and analysis of variance were used. A p-value $<0.05$ was considered significant.

\section{Results}

Methylation of CpG islands in SLIT1, SLIT2 and SLIT3 in gastric cancer. To identify differentially methylated genes in gastric cancer, we performed MBD-seq, a high-throughput sequencing of methylated DNA fragments captured by methyl-CpG-binding domain protein 2 , of patient-derived gastric cancer cells and adjacent normal gastric mucosa cells. Among the differentially methylated regions, we found that 
Table I. Primers for RT-PCR, MSP, and pyrosequencing.

Primers for RT-PCR

\begin{tabular}{lllr}
\hline Gene & Forward primer $\left(5^{\prime}-3^{\prime}\right)$ & Reverse primer $\left(5^{\prime}-3^{\prime}\right)$ & $\begin{array}{c}\text { Annealing } \\
\text { temperature }\left({ }^{\circ} \mathrm{C}\right)\end{array}$ \\
\hline SLIT1 & CTGGTTGCCTTTGACCAGAT & TGTACAGGTTTCGGATGCAA & 60 \\
SLIT2 & TCAAGGTCCTGTGGATGTCA & GTGGCAAGTTCCTCCATGTT & 60 \\
SLIT3 & CCTGCCCCTACAGCTACAAG & TTGTTTTCGCAGTCGTTGTC & 60 \\
\hline
\end{tabular}

Primers for MSP

\begin{tabular}{lllr}
\hline Gene & \multicolumn{1}{c}{ Forward primer (5'-3') } & Reverse primer (5'-3') & $\begin{array}{c}\text { Annealing } \\
\text { temperature }\left({ }^{\circ} \mathrm{C}\right)\end{array}$ \\
\hline SLIT1 & AATTAAGAATTGATATAGCGAGTCG & ACACACACGACGAAAATACG & 57 \\
SLIT2 & GTAGAGCGTCGTTAAGGACGT & CGAAAACTAAAAAACGCGAA & 58 \\
SLIT3 & AATGGAGAGAGCGAGCGTC & AACCCGCGAACCGAATTA & 284 \\
\hline
\end{tabular}

Primers for pyrosequencing

\begin{tabular}{|c|c|c|c|c|c|}
\hline Gene & Forward primer $\left(5^{\prime}-3^{\prime}\right)$ & Reverse primer (5'-3') & Sequencing primer $\left(5^{\prime}-3^{\prime}\right)$ & $\begin{array}{c}\text { Annealing } \\
\text { temperature } \\
\left({ }^{\circ} \mathrm{C}\right)\end{array}$ & $\begin{array}{l}\text { Product } \\
\text { size } \\
\text { (bp) }\end{array}$ \\
\hline SLIT1 & TGGAGGAGTAAGGTGTTTTTTAG & Biotin-ATCAACCCCATAATACCCTC & GAGTAAGGTGTTTTTTAGTT & 60 & 170 \\
\hline SLIT2 & TAAGGAGGGAGTGTTGAGTAGAAA & Biotin-ACTCCCAAACCCCTAACAAAT & TGTTGAGTAGAAAGGGGA & 60 & 212 \\
\hline SLIT3 & GGGGGAGTTTAGTATTTGGGTAT & Biotin-CCACCСCAАAАCCATAАТАТА & GGTTTAGTAGATGGAGTTG & 60 & 282 \\
\hline
\end{tabular}

$\mathrm{CpG}$ islands in SLITs were hypermethylated in gastric cancer (Fig. 1A). To examine the relationship between expression and methylation of SLITs in gastric cancer, we analyzed the expression of SLITs in gastric cancer cell lines using RT-PCR and methylation status using MSP. SLIT1 was repressed in 55\% (6 of 11) of gastric cancer lines, SLIT2 was repressed in 73\% (8 of 11), and SLIT3 was repressed in $82 \%$ (9 of 11) (Fig. 1B). The inactivation of SLITs correlated with $\mathrm{CpG}$ island methylation as revealed by MSP (Fig. 1B). To assess DNA methylation at single-base resolution, we also performed pyrosequencing (Fig. 1C). The gastric cancer cell line SNU-601 had heavily methylated CpG sites of SLITs, but SNU-668 cells showed hypomethylation. In addition, these $\mathrm{CpG}$ sites were hypomethylated in normal tissues and moderately methylated in tumors (Fig. 1C). We next treated SNU-601 and SNU-638 cells with the DNA methylation inhibitor 5-Aza-dC (23) to examine whether the silencing of SLITs in gastric cancer cells could be reversed. Treatment with 5-Aza-dC induced the expression of SLITs (Fig. 1D), suggesting that DNA methylation plays a causal role in SLIT silencing in gastric cancer cells.

Downregulation of SLITs in primary gastric tumors by $\mathrm{Cp} G$ island methylation. We next used qRT-PCR to assess SLIT expression in 96 paired normal and gastric tumor tissues. Data could not be obtained for five tissue pairs for SLIT1 and one tissue pair for SLIT3, so they were omitted from this analysis. Expression of SLIT1, SLIT2 and SLIT3 was significantly reduced in tumors (Fig. 2A). Loss of expression, defined as tumor-specific expression $>2$-fold lower compared with normal tissue, was observed in 76.9\% (70 of 91), 63.2\% (60 of 95), and $72.9 \%$ (70 of 96) of tumors for SLIT1, SLIT2 and SLIT3, respectively. We also measured the methylation levels of SLITS in paired normal and tumor DNAs by pyrosequencing. Among 96 paired normal and tumor tissues used in qRT-PCR, 83 paired DNAs were available for this analysis. One tissue pair for $S L I T 1$, four tissue pairs for $S L I T 2$, and five tissue pairs for SLIT3 were omitted from the analysis because of poor data generation. Tumor DNAs showed a significant methylation increase of 2.3-fold for SLIT1, 2.9-fold for SLIT2, and 1.5-fold for SLIT3 compared with normal tissues (Fig. 2B, p<0.0001). Regression analysis showed that decreased SLIT expression correlated with increased $\mathrm{CpG}$ methylation (Fig. 2C-E). The correlation was highly significant for SLIT2 $(\mathrm{r}=-0.3111$, $\mathrm{p}=0.0056)$ and SLIT3 (r=-0.3531, $\mathrm{p}=0.0015)$ but not significant for SLIT1 ( $\mathrm{r}=-0.1844, \mathrm{p}=0.1082)$.

Methylation status of SLITs during gastric carcinogenesis and aging. Inactivation of SLITs occurred in early-stage as well as in advanced-stage tumors and in both intestinal type and diffuse type (Fig. 3). As expected, based SLIT expression patterns, methylation of SLITs occurred in earlystage and advanced-stage tumors, and both intestinal-type and diffuse-type tumors showed high levels of methylation (Fig. 3). Although no clinical parameter was significantly related to SLIT methylation, we observed a positive correlation of a gradual increase of methylation status with increasing patient age (Fig. 4). Regression analysis revealed a significant correlation for SLIT1 (Fig. 4A, p=0.0067) and SLIT3 (Fig. 4C, 
A MBD-sequencing

(Chr10:98,940,393-98,952,918)

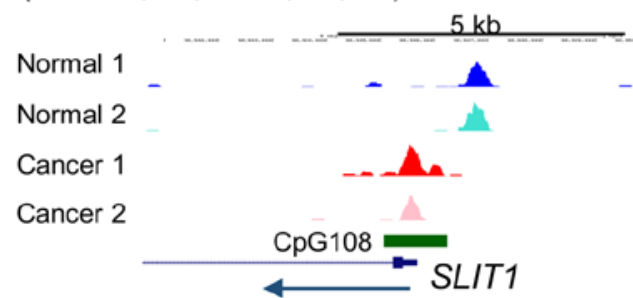

(Chr4:20,243,591-20,267,960)

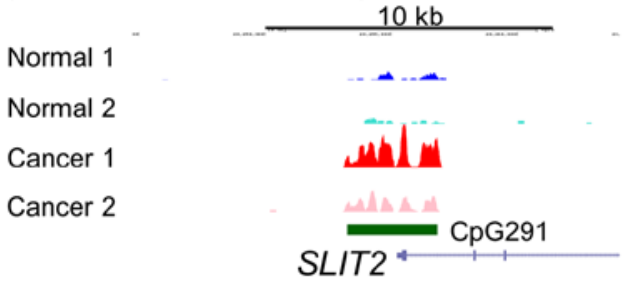

(Chr5:168,715,165-168,736,333)

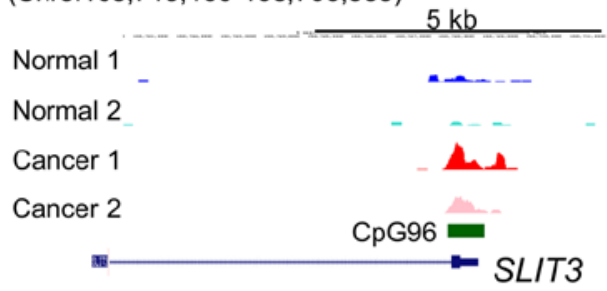

C Pyrosequencing Methyl Unmethyl
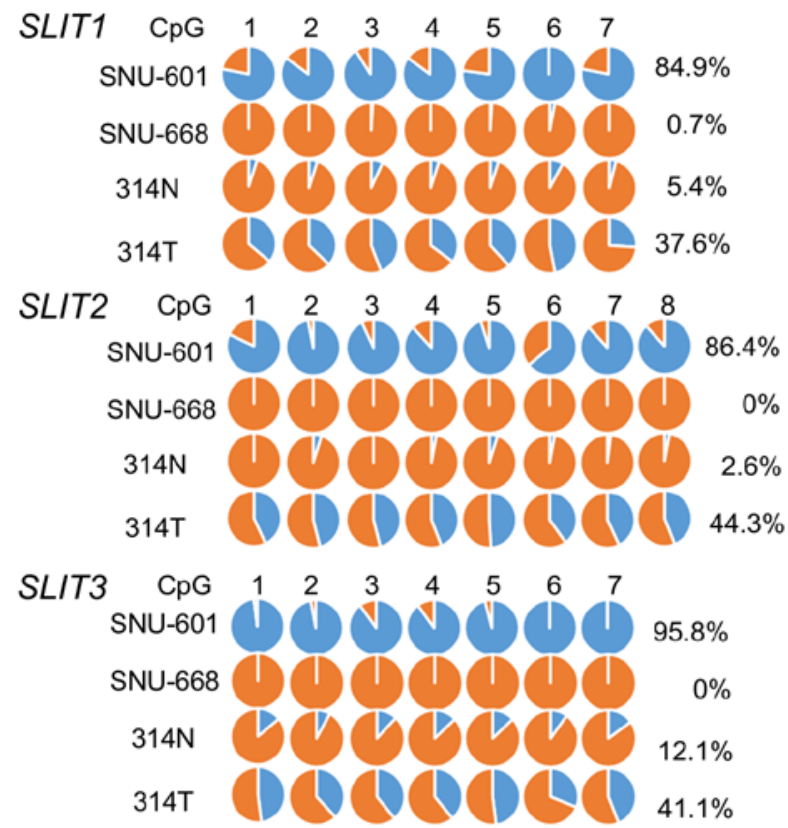

B
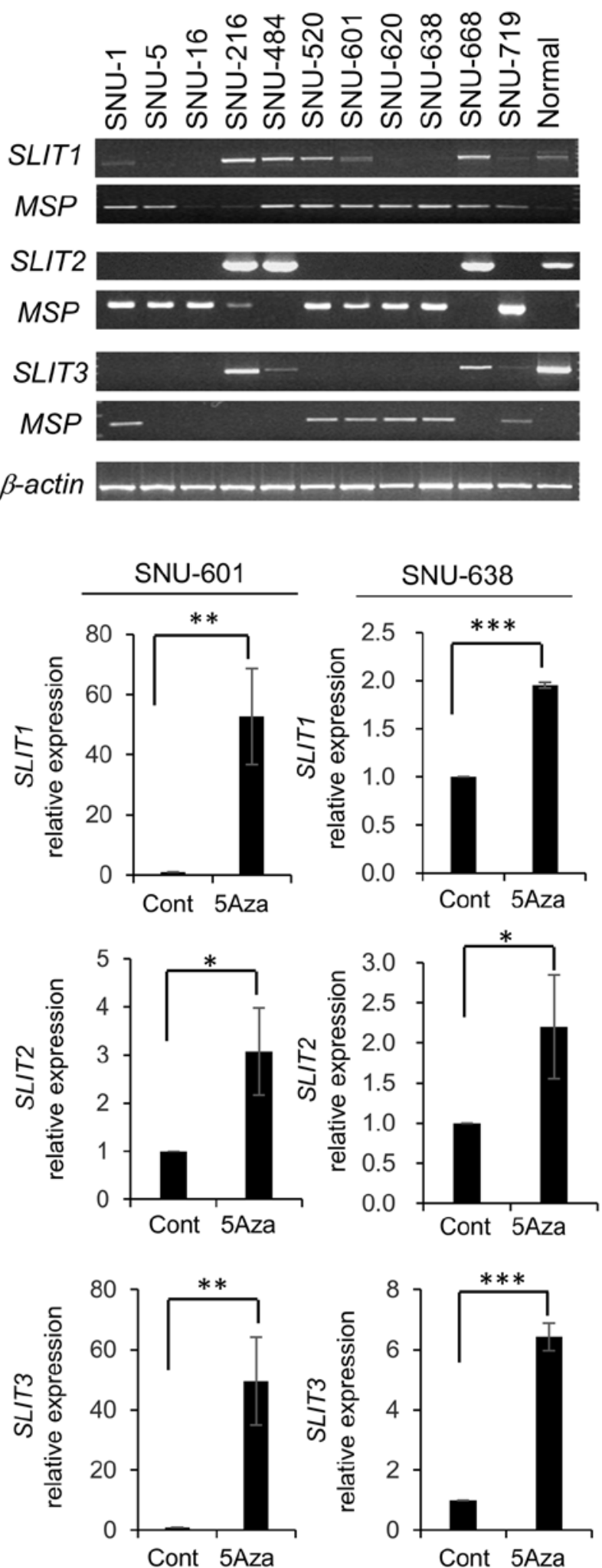

Figure 1. CpG island methylation of SLIT1, SLIT2 and SLIT3 in gastric cancer. (A) MBD-seq data for 5' CpG islands of SLIT1, SLIT2 and SLIT3 in patientderived gastric cancer cells and adjacent normal gastric mucosa cells. (B) RT-PCR and MSP of SLITs in 11 gastric cancer cell lines and normal gastric tissue. (C) Pyrosequencing analysis of SLITs in SNU-601, SNU-668, and paired gastric tumor (314T) and adjacent normal tissue (314N). Mean methylation for each analysis is presented as the percentage on the right. (D) Reactivation of SLITs after treatment with 5-Aza-dC (5Aza) (mean \pm standard error, ${ }^{*} \mathrm{p}<0.05,{ }^{* *} \mathrm{p}<0.01$, **** $\mathrm{p}<0.001)$.

$\mathrm{p}=0.0011$ ) but not for SLIT2 (Fig. 4B, $\mathrm{p}=0.1064$ ) in normal tissues. The positive correlation was also observed in tumor tissues, but the significance was maintained only for SLIT3
(Fig. 4F, p=0.0078). These data suggested that SLIT3 is methylated in both an age- and cancer-related manner, but SLIT2 is methylated only in a cancer-related manner. 
A
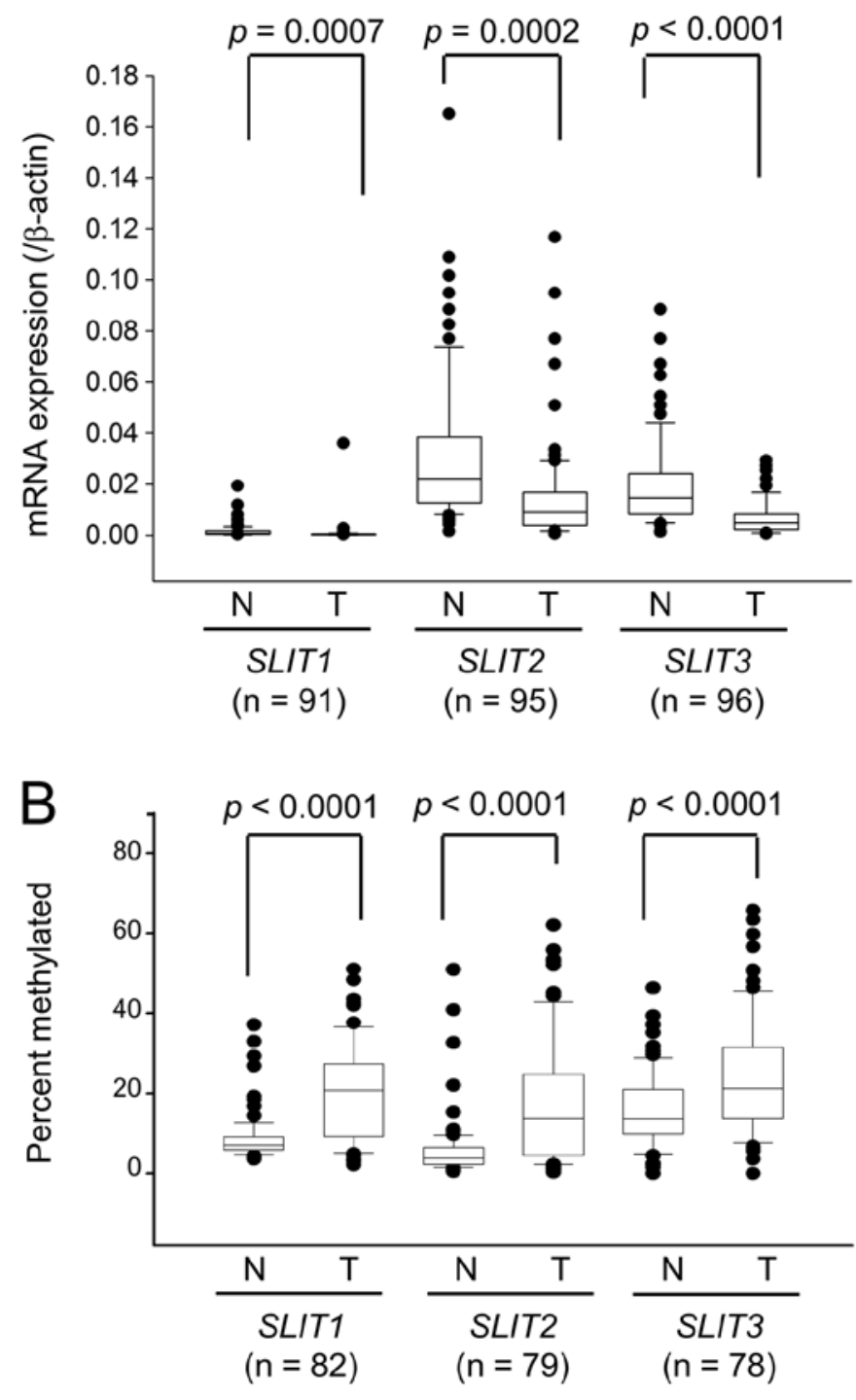

C

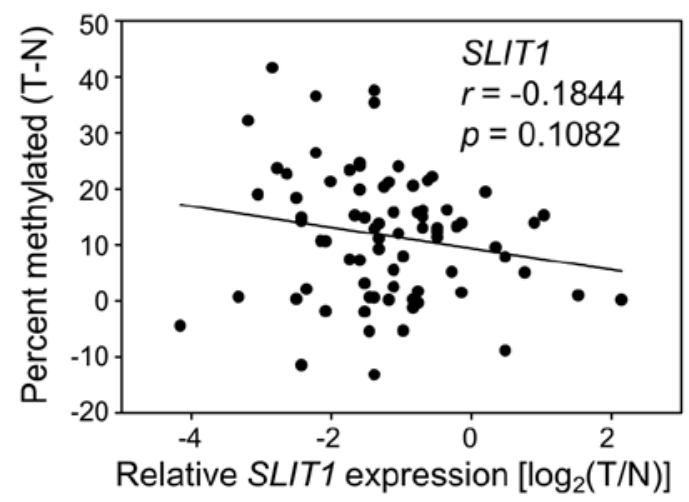

D

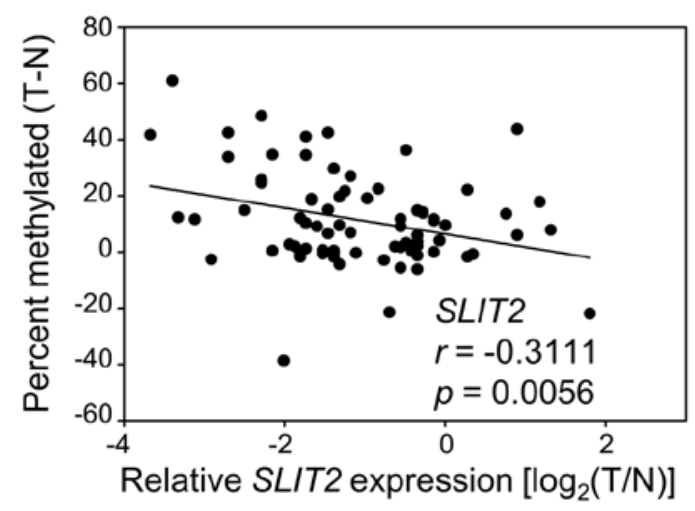

E

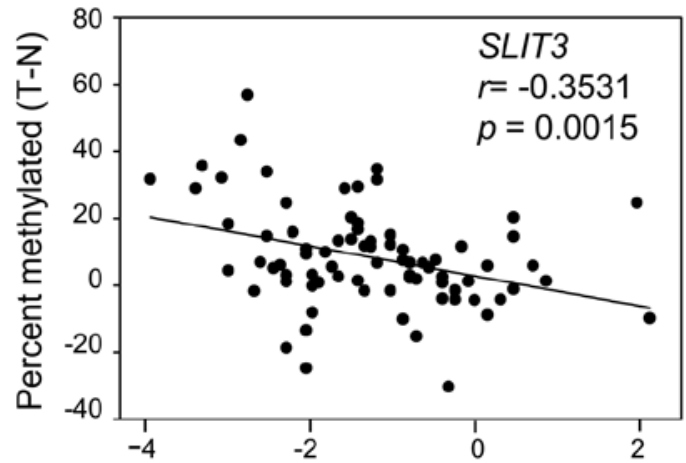

Relative SLIT3 expression $\left[\log _{2}(T / N)\right]$

Figure 2. Expression and methylation of SLIT1, SLIT2 and SLIT3 in primary gastric tumors. (A) SLIT mRNA expression, relative to that of $\beta$-actin, in the paired gastric normal and tumor tissues. The statistical significance of differential expression between normal and tumor tissues was inferred using the paired t-test. Each box plot shows the median and 25th and 75th percentiles, and the dots represent outliers. (B) Methylation of SLITs in the paired gastric normal and tumor tissues. Pyrosequencing analysis was performed at the seven (SLIT1, SLIT3) or eight (SLIT2) CpG sites of the CpG islands. The statistical significance of differential methylation between normal and tumor tissues was inferred using the paired t-test. (C-E) The relationship between SLIT expression and methylation of SLIT1 (C), SLIT2 (D), and SLIT3 (E). This analysis was performed with clinical samples for both expression and methylation data. The methylation change is expressed as the difference between paired tumor and normal tissues (T-N). Expression values are expressed as the $\log _{2}$ ratio of tumor samples over normal samples.

Subtype-specific expression and methylation status of SLITS. To elucidate the specific expression and methylation status of SLITs in gastric cancer subtypes (EBV-positive, MSI, GS, and CIN), we analyzed RNA-seq data and Infinium 450K methylation array data for gastric cancers provided by TCGA (2). TCGA provides methylation array data for 250 gastric tumor samples but only 2 normal samples, so we collected other public data for 10 normal gastric tissue samples $(24,25)$ and data for 1 sample in our laboratory. Fig. 4 shows the methylation profile of the 13 normal gastric tissues and $25 \mathrm{EBV}$,
51 MSI, 52 GS, and 122 CIN subtype gastric cancer tissues in the SLIT1 CpG island (13 CpG sites), SLIT2 CpG island (12 sites), and SLIT3 CpG island (10 sites). SLIT1, SLIT2 and SLIT3 showed similar subtype-dependent methylation patterns (Fig. 5). As expected, the EBV-positive and MSI subtypes had high levels of DNA methylation in the SLIT CpG islands. Although the GS subtype had higher SLIT methylation levels than normal gastric tissue, the methylation differences were slight. The CIN subtype showed a broad range of methylation levels of SLITS promoters (Fig. 5). 
A

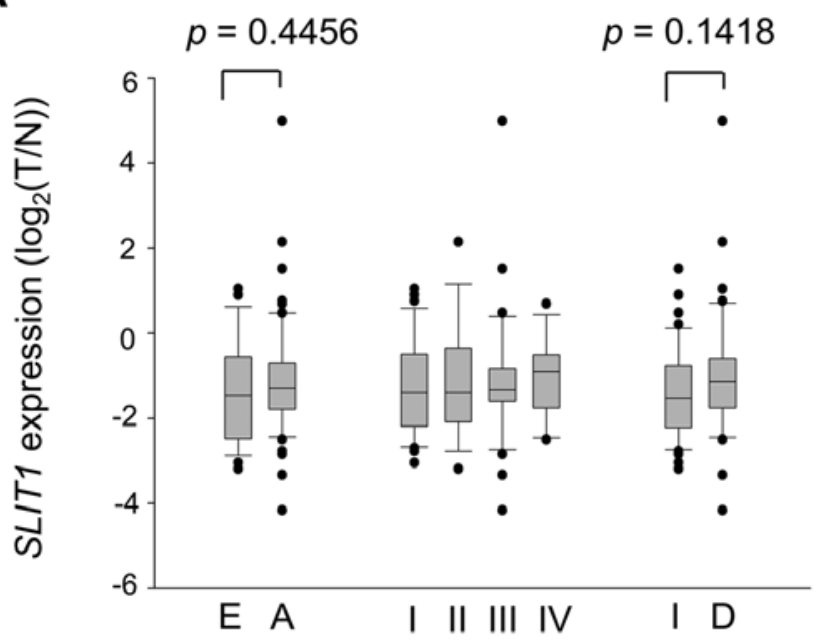

B

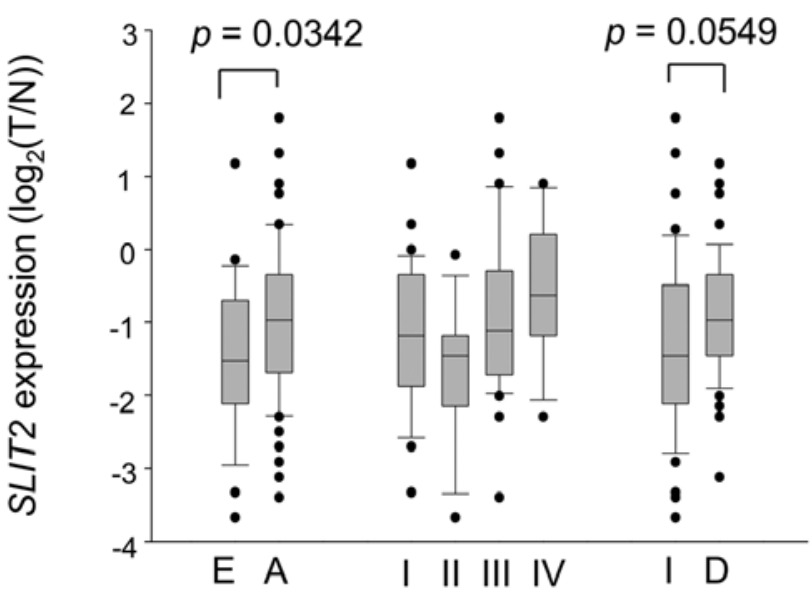

C

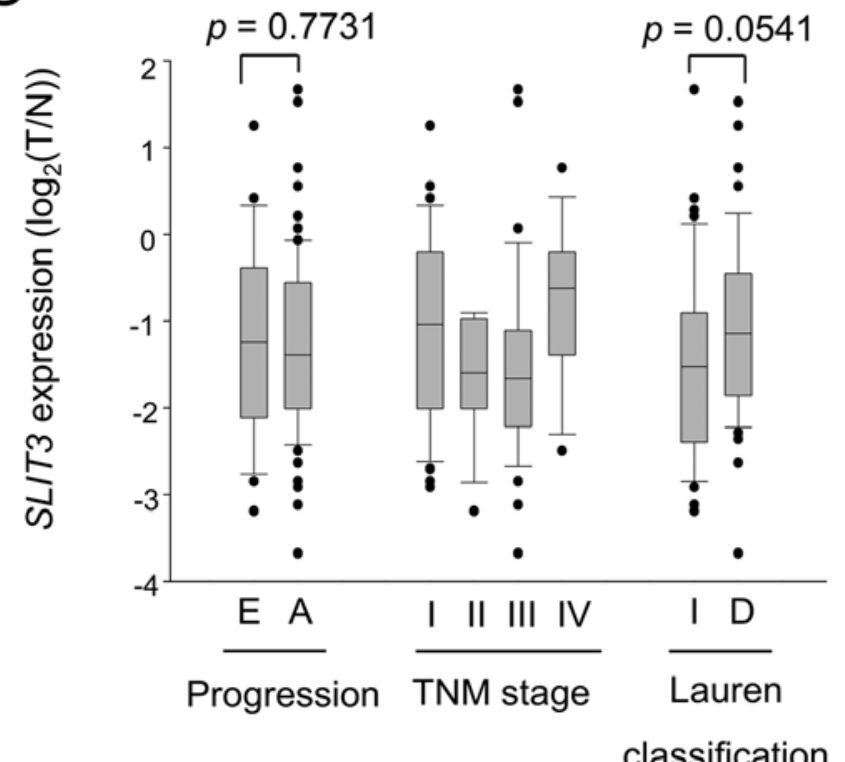

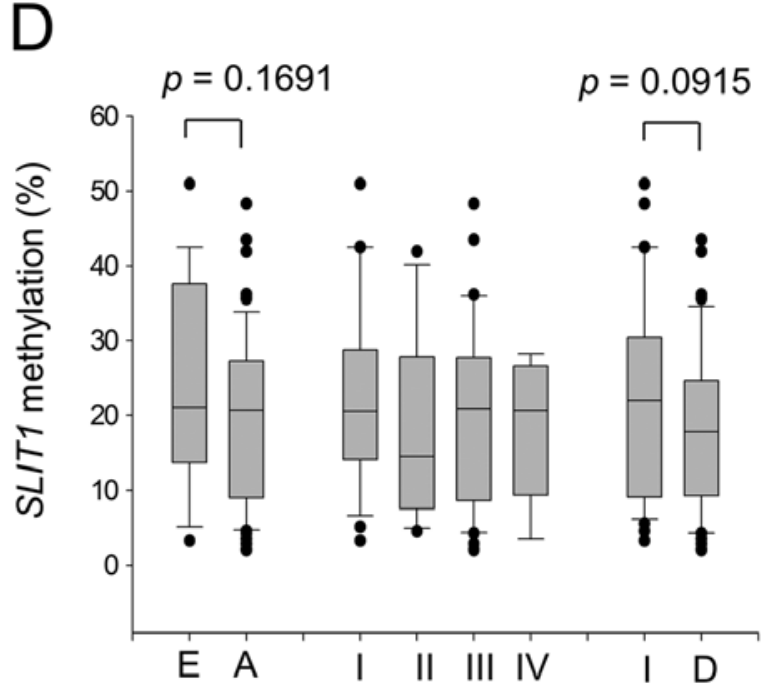

$E$

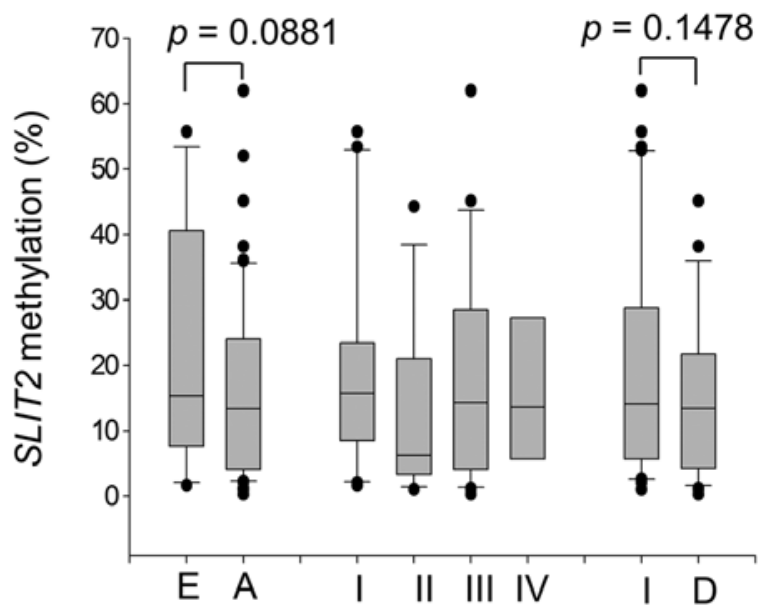

$\mathrm{F}$

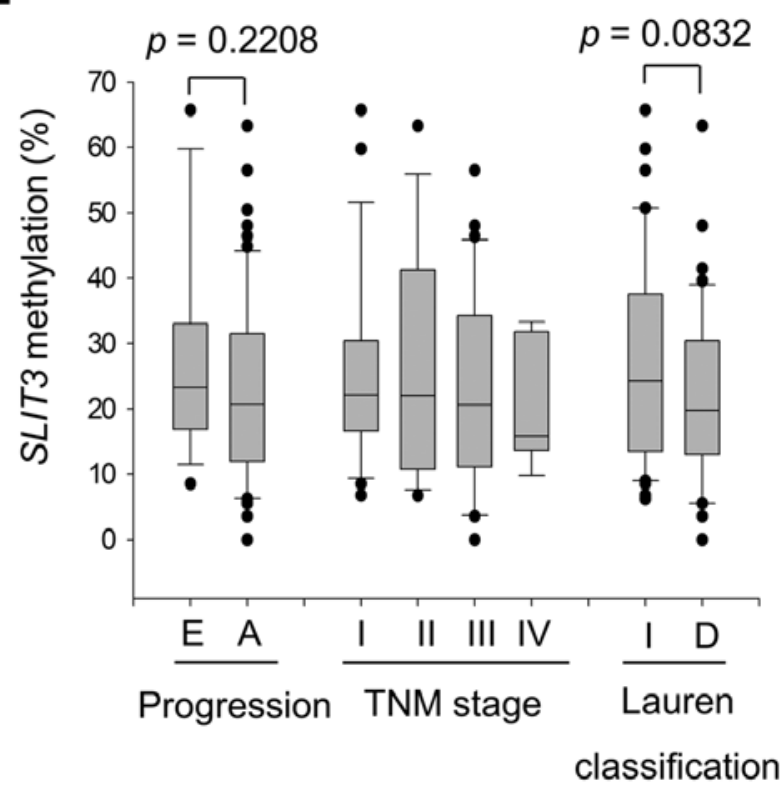

Figure 3. Expression and methylation of SLIT genes in gastric tumors. The expression of SLIT1 (A), SLIT2 (B), and SLIT3 (C) in 96 pairs of normal and tumor tissues was measured by qRT-PCR and is expressed as the $\log _{2}$ ratio of tumor over normal. $\beta$-actin was used as a control. Expression status was stratified by tumor progression (E, early; A, advanced), TNM stage (I, II, III, and IV), and Lauren classification (I, intestinal; D, diffuse). The methylation of promoter regions of SLIT1 (D), SLIT2 (E), and SLIT3 (F) in 83 pairs of normal and tumor tissues was measured by pyrosequencing. Methylation status was stratified by tumor progression, TNM stage, and Lauren classification. Each box plot shows the median and 25 th and 75 th percentiles, and the dots represent outliers. 
A

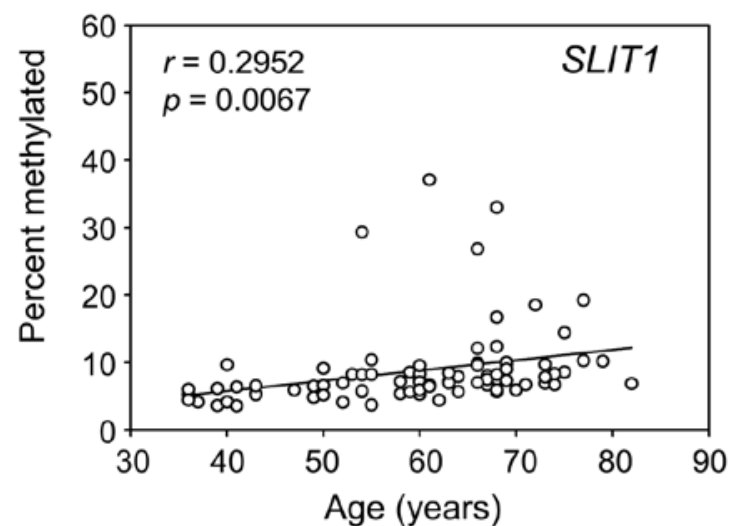

B

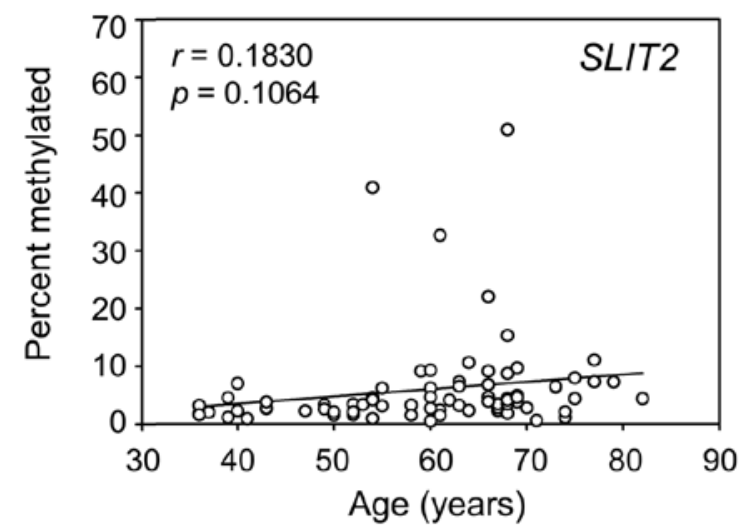

C

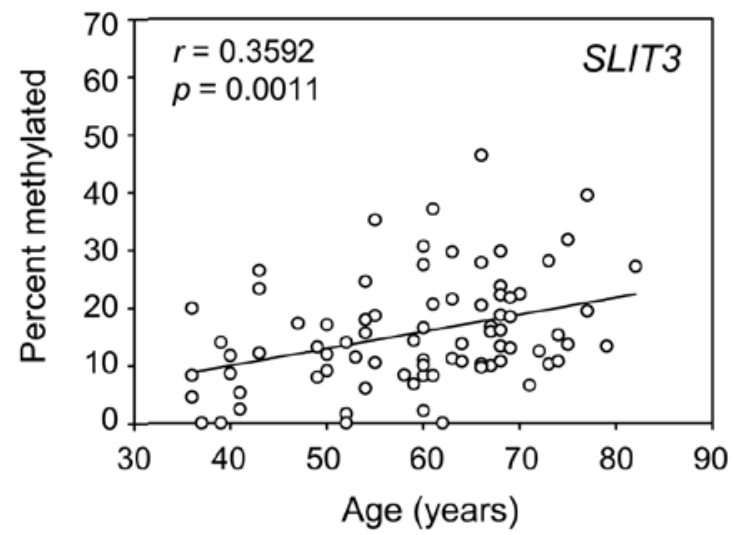

D

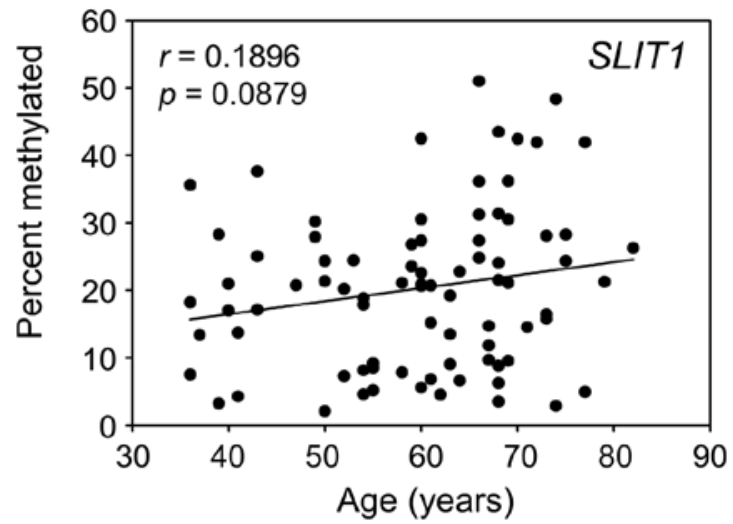

$E$

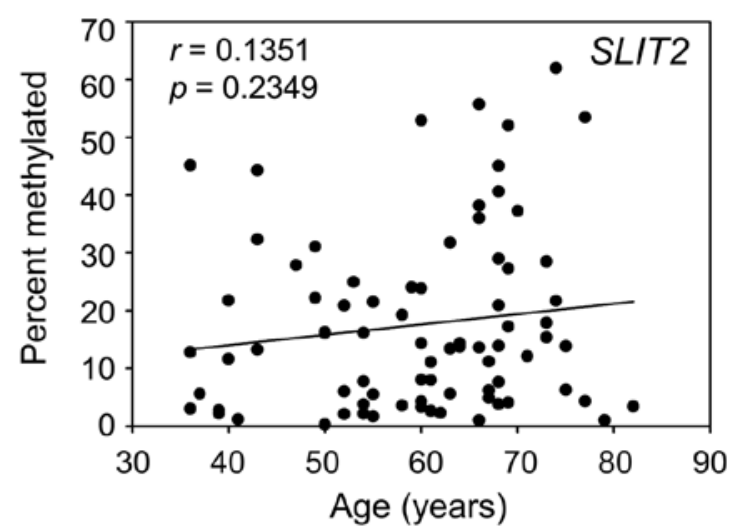

F

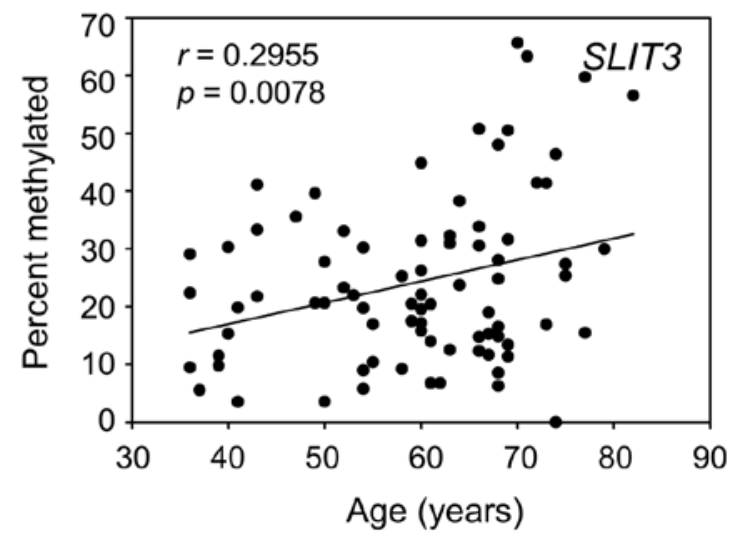

Figure 4. Hypermethylation of SLIT genes with patient age. Regression analysis of SLIT1 (A and D), SLIT2 (B and E), and SLIT3 (C and F) methylation in gastric tumor and adjacent normal tissues according to patient age. Each methylation value from Fig. 2B for each sample was plotted against age. Open circles, normal tissues; filled circles, gastric tumors. Hypermethylation of SLIT genes increases with patient age. The regression coefficient and probability are given in each panel.

As expected from the high methylation levels of SLIT promoters in the EBV and MSI subtypes, these two subtypes had lower SLIT expression than the other subtypes (Fig. 6). Interestingly, expression of SLIT2 and SLIT3 was significantly increased in the GS subtype (Fig. 6B; SLIT2, $\mathrm{p}=0.0062$, Fig. 6C; SLIT3, $\mathrm{p}=0.0027)$. The CIN subtype had SLIT expression levels similar to those of normal gastric tissue (Fig. 6). These data suggested that epigenetic inactivation of SLITS occurs in a subtype-specific manner in gastric cancer.
Downregulation of miR-218 through methylation of SLIT2 and SLIT3 CpG islands. miR-218 is the mature form of miR-218-1 and miR218-2, the intronic miRNAs that share the same promoter with their host gene transcripts, SLIT2 and SLIT3, respectively (15). miRNA-seq of patient-derived gastric cancer cells and adjacent normal gastric mucosa cells showed that expression of miR-218-1 and miR-218-2 was silenced in gastric cancer cells (Fig. 7A and B). To examine the relationship between miR-218-1 and miR-218-2 expression and 


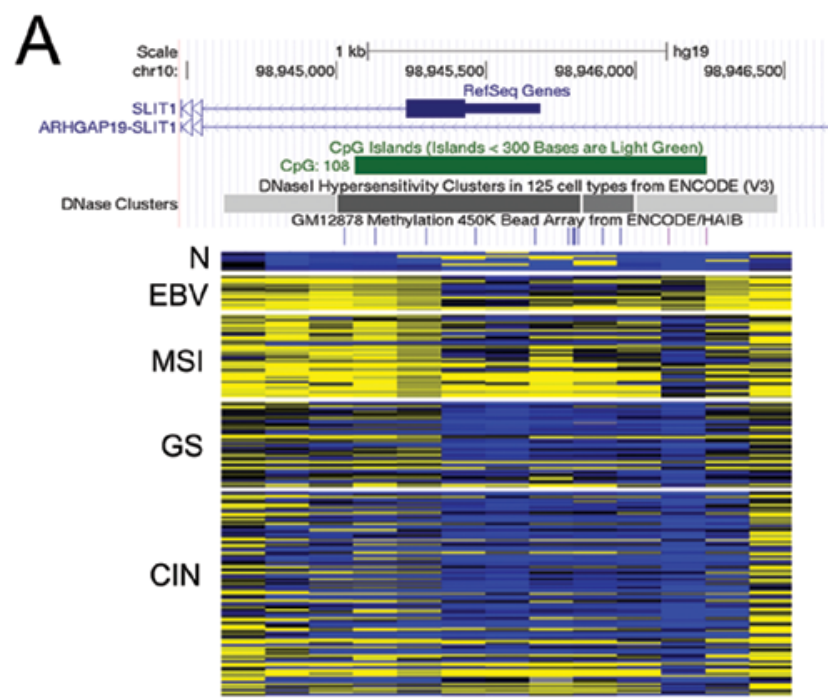

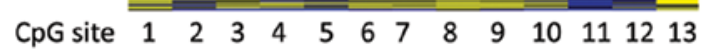
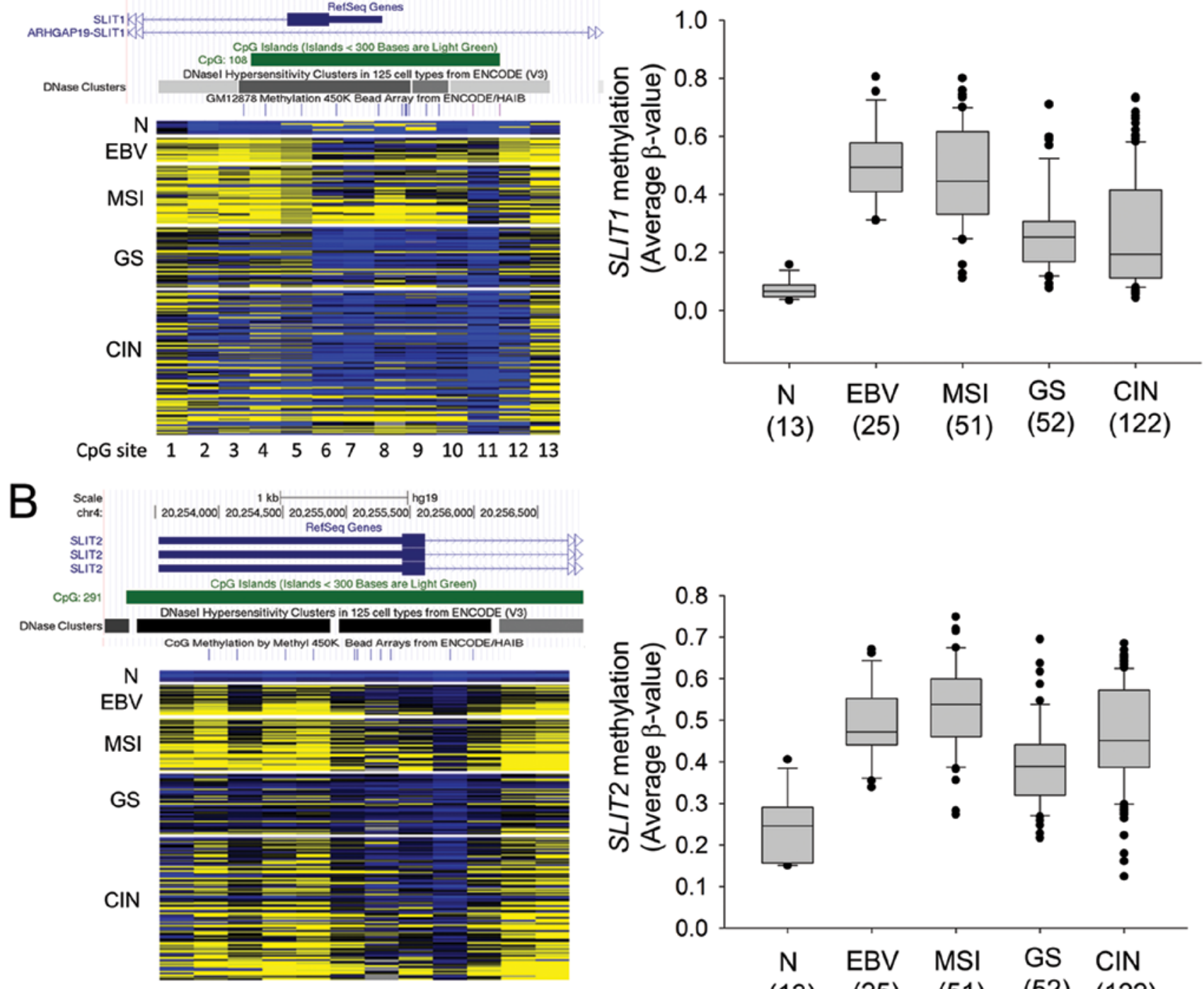

$\begin{array}{llllllllllllll}\text { Cpg site } & 1 & 2 & 3 & 4 & 5 & 6 & 7 & 8 & 9 & 10 & 11 & 12\end{array}$

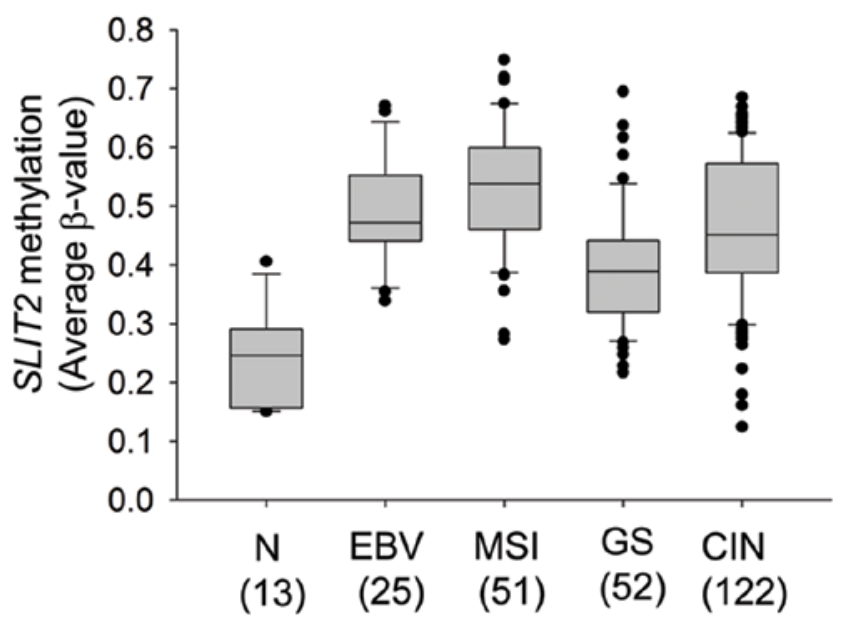

$\mathrm{C}$

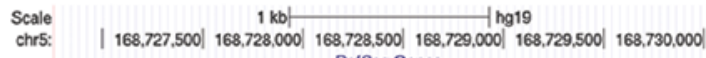
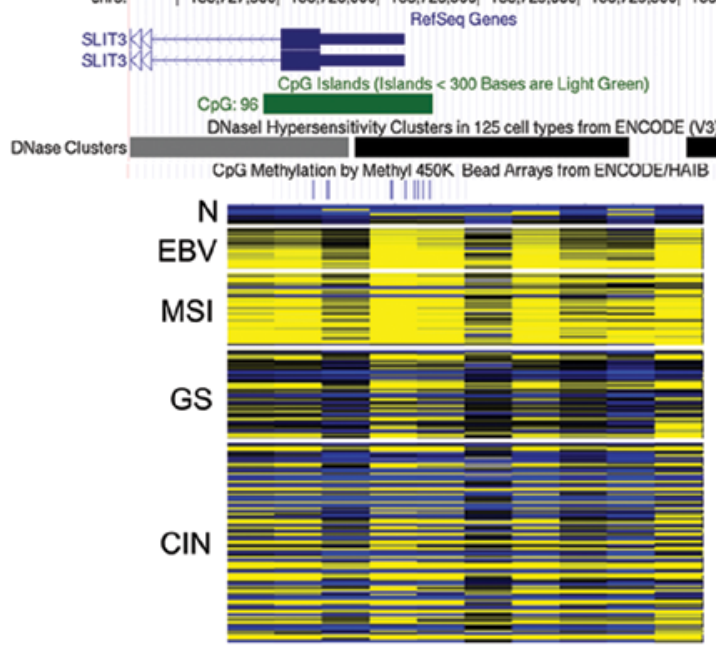

$\begin{array}{lllllllllll}\text { Cpg site } & 1 & 2 & 3 & 4 & 5 & 6 & 7 & 8 & 9 & 10\end{array}$

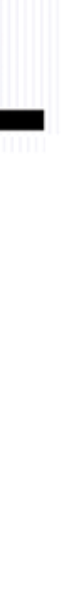

CpG methylation

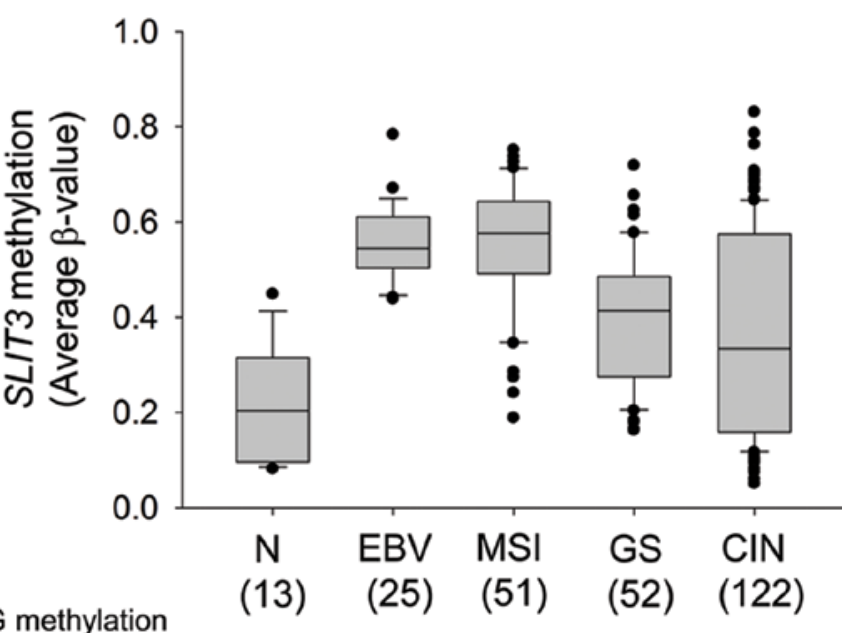

Low

High

Figure 5. Methylation of SLITs in gastric cancer subtypes. Methylation of SLIT1 (A), SLIT2 (B), and SLIT3 (C) in normal gastric tissues (N) and EBV, MSI, GS, and CIN subtypes of gastric cancer tissues. The Infinium 450K methylation array data for gastric cancer was provided by TCGA (2). A snapshot of the UCSC genome browser (http://genome.ucsc.edu/, hg19) shows the locations of CpG sites analyzed in this study. The heatmaps show the methylation status of each CpG site in each tissue sample. Box plots show the median and 25th and 75th percentiles, and the dots represent outliers. 
A

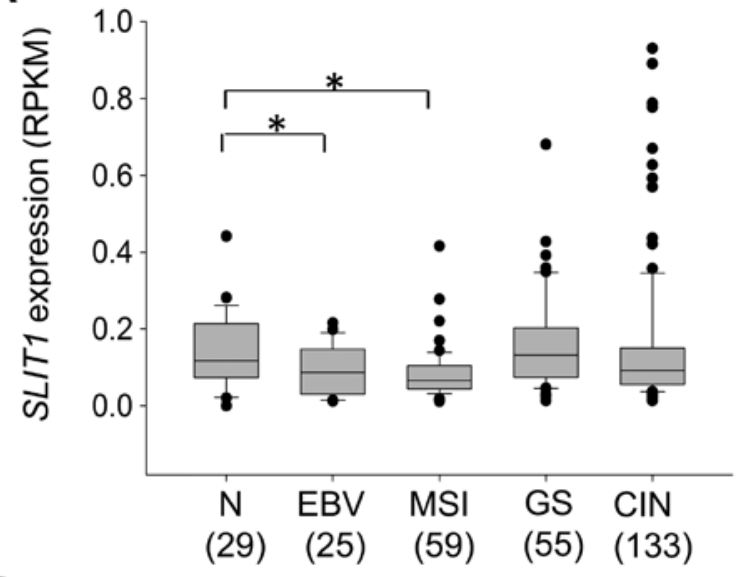

B

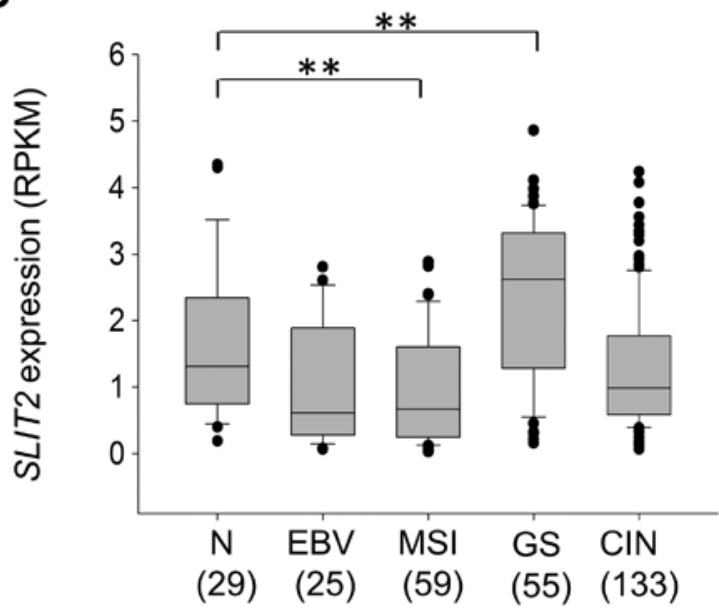

C

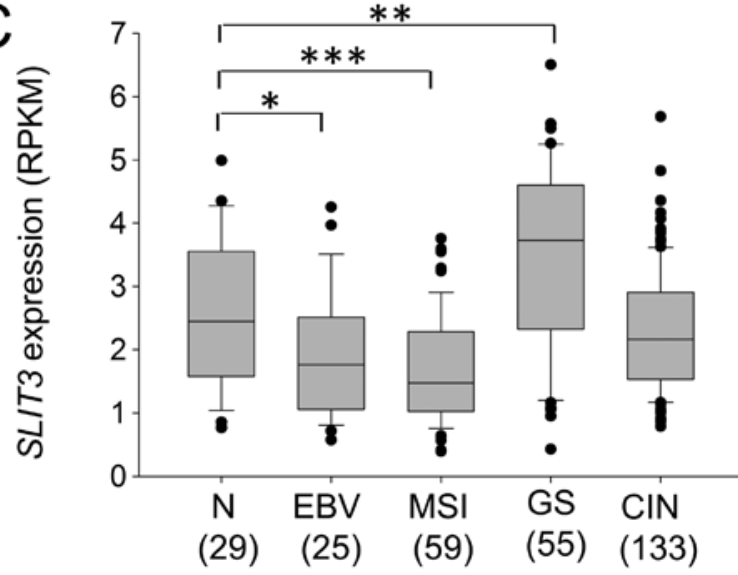

Figure 6. Expression of SLITs in gastric cancer subtypes. Expression of SLIT1 (A), SLIT2 (B), and SLIT3 (C) in normal gastric tissues (N) and EBV, MSI, GS, and CIN subtypes of gastric cancer tissues. RNA-seq data for gastric cancer was provided by TCGA (2). Box plots show the median and 25 th and 75th percentiles, and the dots represent outliers. ${ }^{*} \mathrm{p}<0.05,{ }^{* *} \mathrm{p}<0.01$, **** $\mathrm{p}<0.001$. RPKM, reads per kilobase per million.

CpG island methylation of SLIT2 and SLIT3, we performed regression analysis using TCGA data. Decreasing miR-218-1 and miR-218-2 expression correlated with increasing $\mathrm{CpG}$ methylation of SLIT2 $\left(\mathrm{r}=-0.4070, \mathrm{p}=1 \times 10^{-10}\right)$ and SLIT3 $\left(r=-0.2702, p=3 \times 10^{-5}\right)$, respectively (Fig. 7C and D).

The expression of miR-218-2 was higher than that of miR-218-1 in both gastric normal and tumor tissues (Fig. 7E and F). miR-218-2 expression was lower in EBV, MSI, and CIN subtypes (Fig. 7F), whereas miR-218-1 expression was lower in MSI (Fig. 7E). These data suggested that mature miR-218 is mainly derived from miR-218-2 in gastric cancer, and $\mathrm{CpG}$ island methylation of SLIT3 reduces miR-218 expression in EBV, MSI, and CIN subtypes of gastric cancer.

\section{Discussion}

Recent studies indicated that the SLIT/ROBO pathway has important roles in tumorigenesis, cancer progression, and metastasis $(8,9)$. Furthermore, large-scale genomic studies discovered frequent mutations in SLIT/ROBO pathway genes in gastric cancer (26), pancreatic cancer (27), and small-cell lung cancer (28). These studies suggest that the SLIT/ROBO pathway is a master regulator for multiple oncogenic signaling pathways and a promising target for cancer therapy $(8,9)$.

A methylation analysis of SLIT genes was previously performed using only a few cancer cell lines and primary tumor tissue samples $(12,13)$. In this study, we analyzed expression and methylation of SLITS in 11 gastric cancer cell lines, 96 paired gastric tumors and adjacent normal gastric tissues, and 250 gastric cancers provided by TCGA (2). We found that all three SLIT genes were hypermethylated and downregulated at early stages of gastric cancer (Fig. 3), and hypermethylation was even detected in normal gastric tissues (Fig. 4). Interestingly, methylation of SLIT1 and SLIT3 correlated significantly with age in normal tissues (Fig. 4A and C). These results suggest that loss of SLIT expression is an early event in gastric cancer progression.

SLITs showed subtype-specific expression and methylation. Inactivation of SLITS by $\mathrm{CpG}$ island methylation mainly occurred in the EBV and MSI subtypes (Figs. 5 and 6). Interestingly, the GS subtype showed significantly increased expression of SLIT2 and SLIT3 (Fig. 6B and C). The GS subtype is considered as an aggressive, invasive, and stem-like gastric cancer. Therefore, this result supports the idea that the SLIT/ROBO pathway might inhibit cancer cell migration from the primary site. However, in metastatic tumors, the SLIT/ ROBO system might increase cancer cell motility (9). More basic research is required to better understand the complex functions of these proteins during tumor progression.

The expression of miR-218 is significantly repressed in gastric, colon, prostate, and pancreatic cancers (15). miR-218 suppresses cancer progression by targeting the mRNAs encoding survivin (17), HOXB3 (29), Bmil (30), and components of the AKT/mTOR, SLIT/ROBO, Wnt, and focal adhesion pathways (15). In this study, we found that expression of miR-218-1 and miR-218-2 correlated negatively with $\mathrm{CpG}$ island methylation in SLIT2 and SLIT3, respectively (Fig. 7). According to the expression pattern of their host genes, miR-218-1 and miR-218-2 were expressed in a gastric cancer subtype-specific manner. In particular, miR-218-2 expression was significantly reduced in the EBV and MSI subtypes (Fig. 7F). However, miR-218 expression in the GS subtype did not differ significantly from that in normal tissue. We therefore propose a subtype-specific role for miR-218 in gastric cancer.

In conclusion, we demonstrated that methylation of $\mathrm{CpG}$ islands inactivated SLIT1, SLIT2 and SLIT3 during early gastric tumor progression. SLITS were hypermethylated 
A

(Chr4:20525828-20534077)

$5 \mathrm{~kb}$

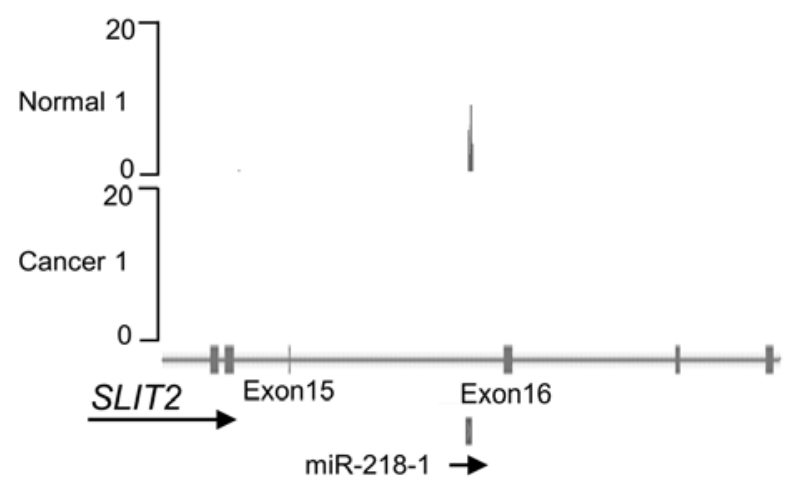

C

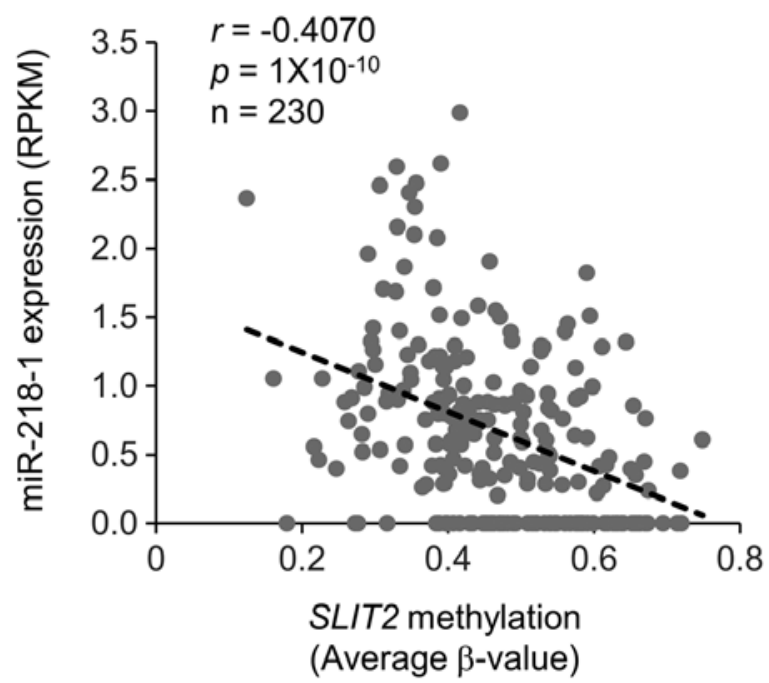

E

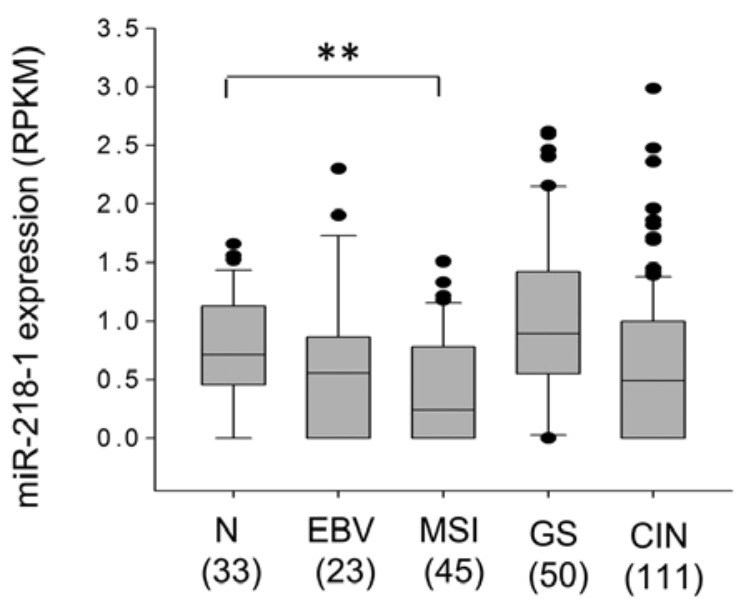

B

(Chr5:168189706-168200705)

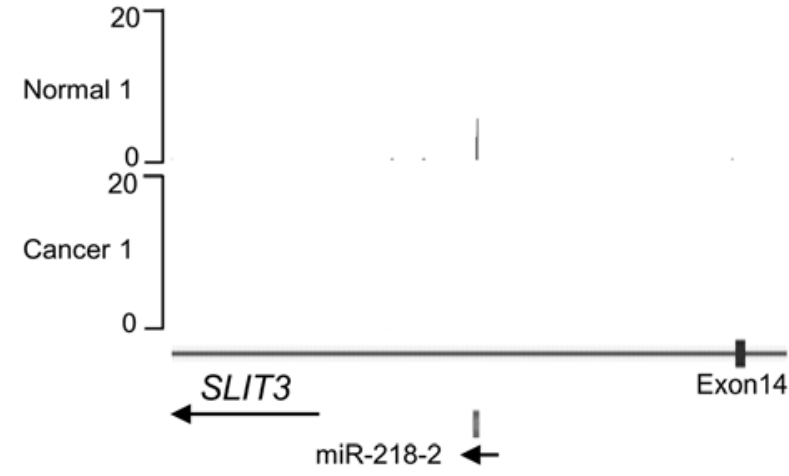

D

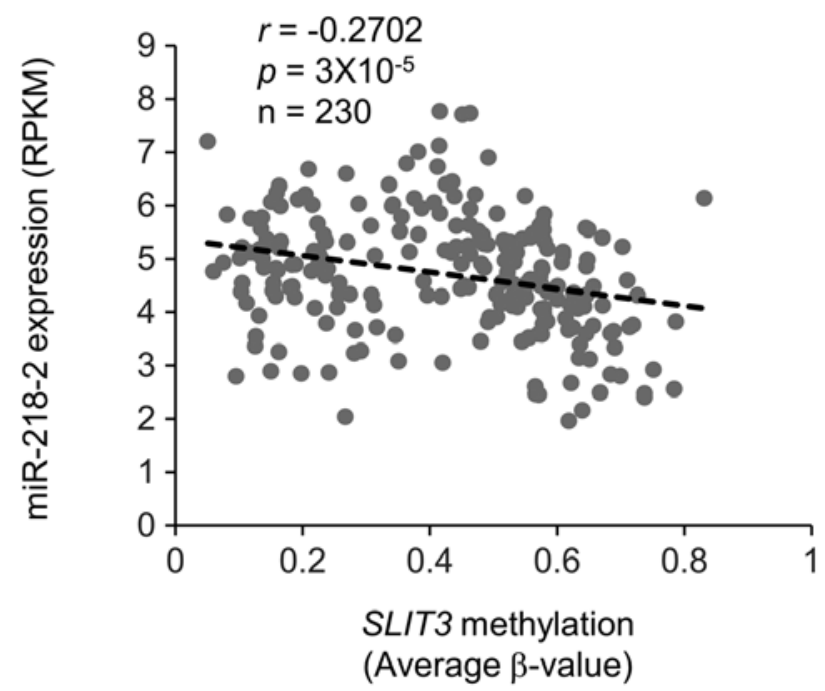

$\mathrm{F}$

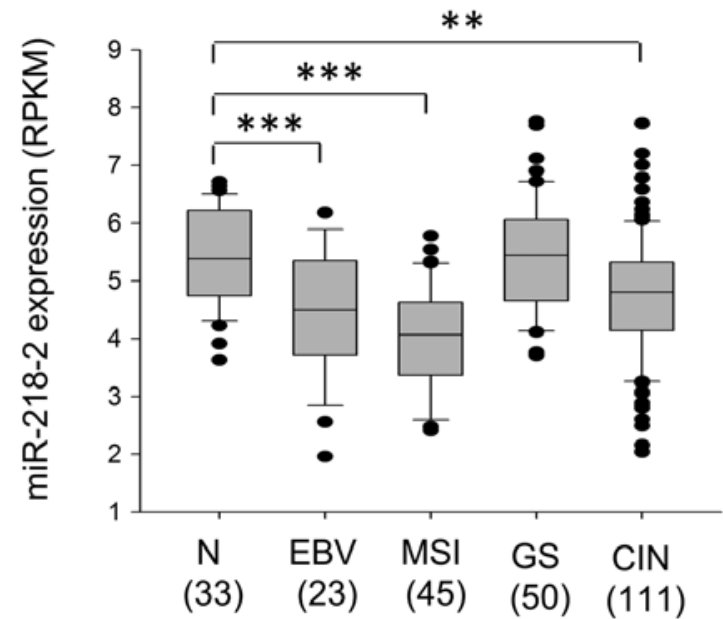

Figure 7. Expression of miR-218-1 and miR-218-2 in gastric cancer. miRNA-seq data for miR-218-2 (A) and miR-218-2 (B) in patient-derived gastric cancer cells and adjacent normal gastric mucosa cells. Relationship between miR-218-1 expression and SLIT2 methylation (C) and miR-218-2 expression and SLIT3 methylation (D). Expression of miR-218-1 (E) and miR-218-2 (F) in normal gastric tissues (N) and EBV, MSI, GS, and CIN subtypes of gastric cancer tissues. Box plots show the median and 25th and 75th percentiles, and the dots represent outliers. ${ }^{*} \mathrm{p}<0.05,{ }^{* *} \mathrm{p}<0.01,{ }^{* * * *} \mathrm{p}<0.001$. RPKM, reads per kilobase per million.

and downregulated in the EBV and MSI subtypes of gastric cancer, whereas SLIT2 and SLIT3 expression increased in the GS subtype. We also showed that miR-218-1 and miR-218-2 expression correlated negatively with $\mathrm{CpG}$ island methylation in SLIT2 and SLIT3, respectively. Although more basic research should be conducted to understand the subtype-specific roles 
of SLITs and miR-218, we suggest that a subtype-specific therapeutic strategy targeting SLITs and miR-218 should be considered for treatment of gastric cancer.

\section{Acknowledgements}

This study was supported by National Research Foundation of Korea (NRF) grants funded by the Korea government (NRF-2012M3A9B4027954 and NRF-2013R1A1A2006621) and a KRIBB research initiative grant.

\section{References}

1. Lauren P: The two histological main types of gastric carcinoma: Diffuse and so-called intestinal-type carcinoma. An attempt at a histo-clinical classification. Acta Pathol Microbiol Scand 64 31-49, 1965.

2. Bass AJ, Thorsson V, Shmulevich I, Reynolds SM, Miller M, Bernard B, Hinoue T, Laird PW, Curtis C, Shen H, et al; Cancer Genome Atlas Research Network: Comprehensive molecular characterization of gastric adenocarcinoma. Nature 513: 202-209, 2014.

3. Fukayama M, Hino R and Uozaki H: Epstein-Barr virus and gastric carcinoma: Virus-host interactions leading to carcinoma. Cancer Sci 99: 1726-1733, 2008.

4. Kaneda A, Matsusaka K, Aburatani H and Fukayama M: EpsteinBarr virus infection as an epigenetic driver of tumorigenesis. Cancer Res 72: 3445-3450, 2012

5. Velho S, Fernandes MS, Leite M, Figueiredo C and Seruca R Causes and consequences of microsatellite instability in gastric carcinogenesis. World J Gastroenterol 20: 16433-16442, 2014.

6. Yamamoto H, Watanabe Y, Maehata T, Morita R, Yoshida Y, Oikawa R, Ishigooka S, Ozawa S, Matsuo Y, Hosoya K, et al: An updated review of gastric cancer in the next-generation sequencing era: Insights from bench to bedside and vice versa. World J Gastroenterol 20: 3927-3937, 2014.

7. Kidd T, Bland KS and Goodman CS: Slit is the midline repellent for the robo receptor in Drosophila. Cell 96: 785-794, 1999.

8. Gara RK, Kumari S, Ganju A, Yallapu MM, Jaggi M and Chauhan SC: Slit/Robo pathway: A promising therapeutic target for cancer. Drug Discov Today 20: 156-164, 2015.

9. Mehlen P, Delloye-Bourgeois C and Chédotal A: Novel roles for Slits and netrins: Axon guidance cues as anticancer targets? Nat Rev Cancer 11: 188-197, 2011.

10. Prasad A, Paruchuri V, Preet A, Latif F and Ganju RK: Slit-2 induces a tumor-suppressive effect by regulating beta-catenin in breast cancer cells. J Biol Chem 283: 26624-26633, 2008.

11. Shi R, Yang Z, Liu W, Liu B, Xu Z and Zhang Z: Knockdown of Slit 2 promotes growth and motility in gastric cancer cells via activation of AKT/ $\beta$-catenin. Oncol Rep 31: 812-818, 2014.

12. Dallol A, Da Silva NF, Viacava P, Minna JD, Bieche I, Maher ER and Latif F: SLIT2, a human homologue of the Drosophila Slit2 gene, has tumor suppressor activity and is frequently inactivated in lung and breast cancers. Cancer Res 62: 5874-5880, 2002

13. Dickinson RE, Dallol A, Bieche I, Krex D, Morton D, Maher ER and Latif F: Epigenetic inactivation of SLIT3 and SLIT1 genes in human cancers. Br J Cancer 91: 2071-2078, 2004.

14. Narayan G, Goparaju C, Arias-Pulido H, Kaufmann AM, Schneider A, Dürst M, Mansukhani M, Pothuri B and Murty VV: Promoter hypermethylation-mediated inactivation of multiple Slit-Robo pathway genes in cervical cancer progression. Mol Cancer 5: 16, 2006.
15. Lu YF, Zhang L, Waye MM, Fu WM and Zhang JF: MiR-218 mediates tumorigenesis and metastasis: Perspectives and implications. Exp Cell Res 334: 173-182, 2015.

16. Tatarano S, Chiyomaru T, Kawakami K, Enokida H, Yoshino H, Hidaka H, Yamasaki T, Kawahara K, Nishiyama K, Seki N, et al: miR-218 on the genomic loss region of chromosome 4p15.31 functions as a tumor suppressor in bladder cancer. Int $\mathrm{J}$ Oncol 39: 13-21, 2011.

17. Alajez NM, Lenarduzzi M, Ito E, Hui AB, Shi W, Bruce J, Yue S, Huang SH, Xu W, Waldron J, et al: MiR-218 suppresses nasopharyngeal cancer progression through downregulation of survivin and the SLIT2-ROBO1 pathway. Cancer Res 71: 2381-2391, 2011.

18. Tie J, Pan Y, Zhao L, Wu K, Liu J, Sun S, Guo X, Wang B, Gang Y,Zhang Y, et al: MiR-218 inhibits invasion and metastasis of gastric cancer by targeting the Robol receptor. PLoS Genet 6 : e1000879, 2010

19. Kim M, Kim JH, Jang HR, Kim HM, Lee CW, Noh SM, Song KS, Cho JS, Jeong HY, Hahn Y, et al: LRRC3B, encoding a leucinerich repeat-containing protein, is a putative tumor suppressor gene in gastric cancer. Cancer Res 68: 7147-7155, 2008.

20. Kim M, Park YK, Kang TW, Lee SH, Rhee YH, Park JL, Kim HJ, Lee D, Lee D, Kim SY, et al: Dynamic changes in DNA methylation and hydroxymethylation when hES cells undergo differentiation toward a neuronal lineage. Hum Mol Genet 23: 657-667, 2014.

21. Haam K, Kim HJ, Lee KT, Kim JH, Kim M, Kim SY, Noh SM, Song KS and Kim YS: Epigenetic silencing of BTB and CNC homology 2 and concerted promoter $\mathrm{CpG}$ methylation in gastric cancer. Cancer Lett 351: 206-214, 2014.

22. Kim SK, Jang HR, Kim JH, Kim M, Noh SM, Song KS, Kang GH, Kim HJ, Kim SY, Yoo HS, et al: CpG methylation in exon 1 of transcription factor 4 increases with age in normal gastric mucosa and is associated with gene silencing in intestinal-type gastric cancers. Carcinogenesis 29: 1623-1631, 2008.

23. Jones PA and Taylor SM: Cellular differentiation, cytidine analogs and DNA methylation. Cell 20: 85-93, 1980.

24. Lokk K, Modhukur V, Rajashekar B, Märtens K, Mägi R, Kolde R, Koltšina M, Nilsson TK, Vilo J, Salumets A, et al: DNA methylome profiling of human tissues identifies global and tissue-specific methylation patterns. Genome Biol 15: r54, 2014.

25. Nazor KL, Altun G, Lynch C, Tran H, Harness JV, Slavin I, Garitaonandia I, Müller FJ, Wang YC, Boscolo FS, et al: Recurrent variations in DNA methylation in human pluripotent stem cells and their differentiated derivatives. Cell Stem Cell 10: 620-634, 2012

26. Wong SS, Kim KM, Ting JC, Yu K, Fu J, Liu S, Cristescu R, Nebozhyn M, Gong L, Yue YG, et al: Genomic landscape and genetic heterogeneity in gastric adenocarcinoma revealed by whole-genome sequencing. Nat Commun 5: 5477, 2014.

27. Biankin AV, Waddell N, Kassahn KS, Gingras MC, Muthuswamy LB, Johns AL, Miller DK, Wilson PJ, Patch AM, Wu J, et al; Australian Pancreatic Cancer Genome Initiative: Pancreatic cancer genomes reveal aberrations in axon guidance pathway genes. Nature 491: 399-405, 2012.

28. Peifer M, Fernández-Cuesta L, Sos ML, George J, Seidel D, Kasper LH, Plenker D, Leenders F, Sun R, Zander T, et al: Integrative genome analyses identify key somatic driver mutations of small-cell lung cancer. Nat Genet 44: 1104-1110, 2012.

29. Li Q, Zhu F and Chen P: miR-7 and miR-218 epigenetically control tumor suppressor genes RASSF1A and Claudin-6 by targeting HoxB3 in breast cancer. Biochem Biophys Res Commun 424: 28-33, 2012

30. Tu Y, Gao X, Li G, Fu H, Cui D, Liu H, Jin W and Zhang Y: MicroRNA-218 inhibits glioma invasion, migration, proliferation, and cancer stem-like cell self-renewal by targeting the polycomb group gene Bmi1. Cancer Res 73: 6046-6055, 2013. 